Chen, Y., Li, R., \& Liu, X. (2021). The relationships among relatedness frustration, affiliation motivation, and WeChat engagement, moderated by relatedness satisfaction. Cyberpsychology: Journal of Psychosocial Research on Cyberspace, 15(4), Article 7. https://doi.org/10.5817/CP2021-4-7

\title{
The Relationships Among Relatedness Frustration, Affiliation Motivation, and WeChat Engagement, Moderated by Relatedness Satisfaction
}

Yunxiang Chen, Ruoxuan Li, \& Xiangping Liu

Faculty of Psychology, Beijing Normal University, Beijing, PR China

\begin{abstract}
The current study was designed based on the two-process model of the relatedness need to investigate the cyberpsychological mechanisms in the relationship between relatedness frustration and social networking sites (SNSs) behaviors. Chinese college students $\left(N=494 ; 190\right.$ males; $\left.M_{\text {age }}=18.81 \pm .92\right)$ were recruited to complete online questionnaires to measure relatedness frustration, relatedness satisfaction, affiliation motivation, and WeChat engagement. Path analyses indicated that relatedness frustration was directly related to defensive WeChat engagement and indirectly related to WeChat involvement and active engagement via affiliation motivation. Affiliation motivation played a significant mediating role, with the relationship between affiliation motivation and WeChat involvement being moderated by relatedness satisfaction. Specifically, this relationship existed only when the level of relatedness satisfaction was high. This study helps to understand motivational coping mechanisms among people with different levels of relatedness satisfaction in relation to SNSs after experiencing relatedness frustration. Potential limitations and future directions of this paper to the cyber-psychology literature are discussed.
\end{abstract}

Keywords: Relatedness frustration; affiliation motivation; WeChat engagement; moderation; relatedness satisfaction

\section{Introduction}

Social networking sites (SNSs) are popular platforms for online interaction (Hughes et al., 2012). Using SNSs, such as Facebook in the United States and WeChat (Chinese pinyin: Weixin) in China, people exchange information, express themselves, participate in interactions, and maintain contact with others (Sultan, 2014). In China, WeChat has experienced explosive growth in popularity in the past decade. WeChat is a free mobile application developed by Tencent in China. This software, similar to Facebook, allows people to privately interact with acquaintances via instant text and voice message, to post status updates, or "Moments", and to comment on the posts of their friends. WeChat provides a convenient and timely way for users to communicate and thereby creates practical social circles in a virtual environment.

Research has shown that SNSs improve people's life satisfaction and wellness (Wen et al., 2016). People enjoy the online interaction with others and feel a high level of social belonging (Chiou et al., 2014; Knowles et al., 2015). However, many studies have proved that excessive use of SNSs leads to loneliness, low levels of social support, and poor social skills (Hou et al., 2017, 2018). These contradictory findings could be understood by considering the style of social network engagement (Y. Chen et al., 2019; Gerson et al., 2017). Active engagement and 
involvement can improve people's personal wellness, while defensive and passive engagement can lead to illness and maladjustment (e.g., Trifiro \& Gerson, 2019; Wang et al., 2018; Yu, 2016). Hence, it is of great practical significance to explore the cyber-psychological mechanism in SNSs behaviors, such as WeChat engagement, and engagement styles.

\section{The Two-Process Model of Relatedness Need}

In research on SNSs, the two-process model (TPM) of relatedness need defines a pivotal position (Sheldon et al., 2011). Relatedness need, which is one of three basic needs (i.e., autonomy, competence, and relatedness; Deci \& R. M. Ryan, 2008), is defined as the need for social connectedness. In the TPM framework (Prentice et al., 2014; Sheldon, 2011), relatedness-need frustration (RNF) and satisfaction (RNS) are defined as follows: RNF is associated with feelings of exclusion and loneliness (Cordeiro et al., 2016), while RNS is associated with feelings of belongingness within supportive relations (Baumeister \& Leary, 1995).

RNF and RNS are involved in two main functional processes: the need-as-motive process and the need-asrequirement process (Sheldon et al., 2011). The need-as-motive process happens prior to a person's behavior; RNF is the cause of behavior and motivates behavior, and thus it is related to subsequent behaviors (Prentice et al., 2014). The need-as-requirement process occurs after a person's behavior; during this process, RNS is the result of the behavior and functions as an experiential requirement that originates from anteceding behaviors (Sheldon, 2011). In the present study, the need-as-motive process was used as the theoretical basis for exploring the influencing factors and underlying mechanism of WeChat engagement.

\section{Relatedness Frustration and WeChat Engagement}

In terms of the WeChat engagement, three styles (i.e., involvement, active engagement, and defensive engagement) have been theoretically and empirically confirmed as distinct constructs (Y. Chen et al., 2019). Involvement is an evaluation of a user's engagement that considers the degree of involvement in WeChat in terms of, for example, the number of online friends and chat groups, chat frequency, and the amount of daily use. Active engagement is defined based on the degree of active WeChat use and the level of participation in positive interactions, such as sharing, posting status updates, and discussing updates with others. Defensive engagement is defined by defensive WeChat use and the level of participation in self-protective behaviors, such as blocking other users, refusing to see others' updates, and keeping others from seeing one's own updates. These three types of WeChat engagement are correlated.

Previous studies have explored the role of personality factors and adaptability on social media use (He et al., 2017; Hou et al., 2018; Y. Z. Jiang et al., 2017), but relatedness frustration is also an important factor. Individuals use SNSs to feel social connectedness and compensate for their inability to meet their relatedness needs in the real world (Skues et al., 2012). However, in the context of WeChat, it has been found that RNF is related to defensive use only, and no relationship was found between RNF and involvement as well as active use (Y. Chen et al., 2019). Self-determination theory suggests that individuals' need frustration might result in oppositional defiance, which reflects people's resistance to conforming to social rules (Van Petegem et al., 2013; Vansteenkiste \& R. M. Ryan, 2013). In SNSs, making new friends, joining chat groups (i.e., involvement), and interacting with others through sharing and commenting (i.e., active use) are basic social rules and forms of socialization. But due to frustrated relatedness, people might refuse to follow such rules and socializing process. Given the fact that individuals who are frustrated with relatedness need are unable to get enough satisfaction from their social interactions (Moller et al., 2010). In the long run, individuals who experience RNF do not get involved or actively use SNSs afterwards since they know that these behaviors are ineffective. Instead, they might engage in defensive SNSs behaviors to protect themselves and avoid further frustration. Therefore, RNF may be directly related to defensive WeChat engagement only.

\section{Motivational Mechanism Between RNF and WeChat Engagement}

In TPM, the need-as-motive process assumes that negative life events frustrate a person's relatedness need, which motivates the person to pursue social interactions through, for example, SNSs activities such as WeChat engagement. SNSs are platforms used to seek affiliation (Park et al., 2011; Sheldon et al., 2011). In the field of 
rejection research, similar findings were discussed. Social rejection triggers relatedness frustration (Gerber \& Wheeler, 2009; Williams, 2009), which drives people to obtain social reconnection and consequently increases affiliation behaviors (Chester et al., 2016). Research on the motivation of WeChat use also indicated that most users use WeChat to maintain or enhance relationships with acquaintances (Chiou et al., 2015). Hence, it is reasonable to suppose that affiliation motivation might help to explain the link between relatedness frustration and WeChat engagement. Affiliation motivation was defined as a motivation for staying with friends, willingness to accept others, and desire to build friendships and maintain long-term contact with others (Langan-Fox \& Grant, 2006; Smith, 2008).

Relatedness frustration spurs affiliation motivation, which in turn results in WeChat involvement and active engagement. In the context of Facebook, Sheldon and colleagues (Sheldon et al., 2011) found that a feeling of disconnectedness is indirectly related to Facebook involvement (use frequency) because people use Facebook to "cope with disconnectedness". This motive, induced by frustrated relatedness, causes people to immerse themselves in Facebook. In Sheldon et al.'s later Facebook-deprivation experiment showed similar results with regard to active Facebook engagement. Social rejection leads to relatedness frustration and motivates an individual to meet new people, cooperate, and make positive evaluations (Maner et al., 2007). Such affiliation motivation has been shown to greatly predict SNSs involvement (i.e., the number of online friends and amount of daily use) and active engagement (i.e., posting photos and publishing messages) (Heser et al., 2015).

Affiliation motivation also plays an intervening role in the link between relatedness frustration and defensive engagement. In the context of Renren, a popular Chinese site similar to Facebook (Qiu et al., 2013), Zhou (2014) found that, when people feel a high level of relatedness frustration, they show passive, defensive, and selfprotective behaviors on the site. For example, they unilaterally read status updates and logs without any posting any replies or comments. More importantly, these people consider these online behaviors as a way to cope with feelings of disconnection. A recent study indicated that, after relatedness frustration, people were motivated to restore social connectedness (Neubauer et al., 2018). In prior studies concerning competence and autonomy frustration, similar findings have been demonstrated (Fang et al., 2018; Radel et al., 2011). Similar to the Renren case, affiliation motivation might also work as a coping strategy when a person experiences relatedness frustration and defensively engages in WeChat.

\section{Moderation Role of Relatedness Satisfaction}

TPM proposes an interaction of the two processes, which is the rationale for exploring the moderation mechanism in RNF, affiliation motivation, and three sorts of WeChat engagement. Within the need-as-motive process, particularly the relation of motivation and subsequent behaviors, the result of the need-as-requirement process (namely, RNS) has an impact. The strength of this relationship depends on the experience of RNS. Individuals with high RNS show more motive-related behaviors under the same intensity of motive than those with low RNS. Namely, anteceding behaviors lead to RNS, which could interact with subsequent motivation to influence subsequent behaviors. RNS is both the result of anteceding behaviors and, together with motivation, affects subsequent behaviors.

In research on competence need, competence satisfaction was shown to moderate the relationship between achievement motivation and subsequent behaviors (Schüler et al., 2010). For those with high competence satisfaction, achievement motivation can be used to predict goal-attaining behaviors. For those with low competence satisfaction, such prediction is not possible. Competence satisfaction serves a reinforcing function that makes it easier for individuals with high achievement motivation to accomplish their goals. In WeChat, RNS might also play a reinforcing role. Individuals with high RNS might show closer ties between affiliation motivation and the three types of WeChat engagement than those with low RNS. Therefore, these types of WeChat engagement can be considered goal-attaining behaviors used to cope with relatedness frustration or affiliation motivation.

\section{The Current Study}

The current study uses WeChat to investigate the relationship between RNF and social media engagement and to examine the mediating role of affiliation motivation and the moderating role of RNS. The mediation effect is 
directed by the need-as-motive process of TPM, and the moderation effect directed by the interaction of the two processes in TPM.

As for the study's motivation and contribution to scholarly literature, they could be explained in three ways. First, while previous research explored WeChat use as a unidimensional construct (Hou et al., 2017; Wen et al., 2016), this study considered it in terms of three engagement styles. Different types of WeChat engagement were also explored in relation to RNF and affiliation motivation. Second, TPM was proposed and built in the Western context (i.e., Facebook domain; Sheldon et al., 2011). The motivation of this study was to verify TPM's need-as-motive process and interaction assumption in the context of Chinese culture (i.e., WeChat domain). Specifically, people with different levels of RNS might show different coping mechanism in terms of the relations among RNF, motivation, and WeChat use. Finally, to the best of our knowledge, there is currently no research considering such a dynamic mechanism during the link of need frustration and coping behaviors in the context of SNSs. This study contributes to the cyber-psychology literature and helps demystify SNSs behavior.

This study makes the following hypotheses: a) among the three WeChat engagement types, only RNF is directly and positively related to defensive engagement; b) RNF could be indirectly related to three engagements through affiliation motivation, that is, RNF is positively related to this motivation and thus positively related to the three engagement types; c) the link between motivation and engagement could be moderated by RNS (see Figure 1), and specifically, this link is found for people with high RNS only. Additionally, although affiliation motivation includes implicit and explicit components, this study focuses on the role of explicit motivation since implicit motivation has no association with social network engagement (Heser et al., 2015).

Figure 1. The Hypothesized Conceptual Model.

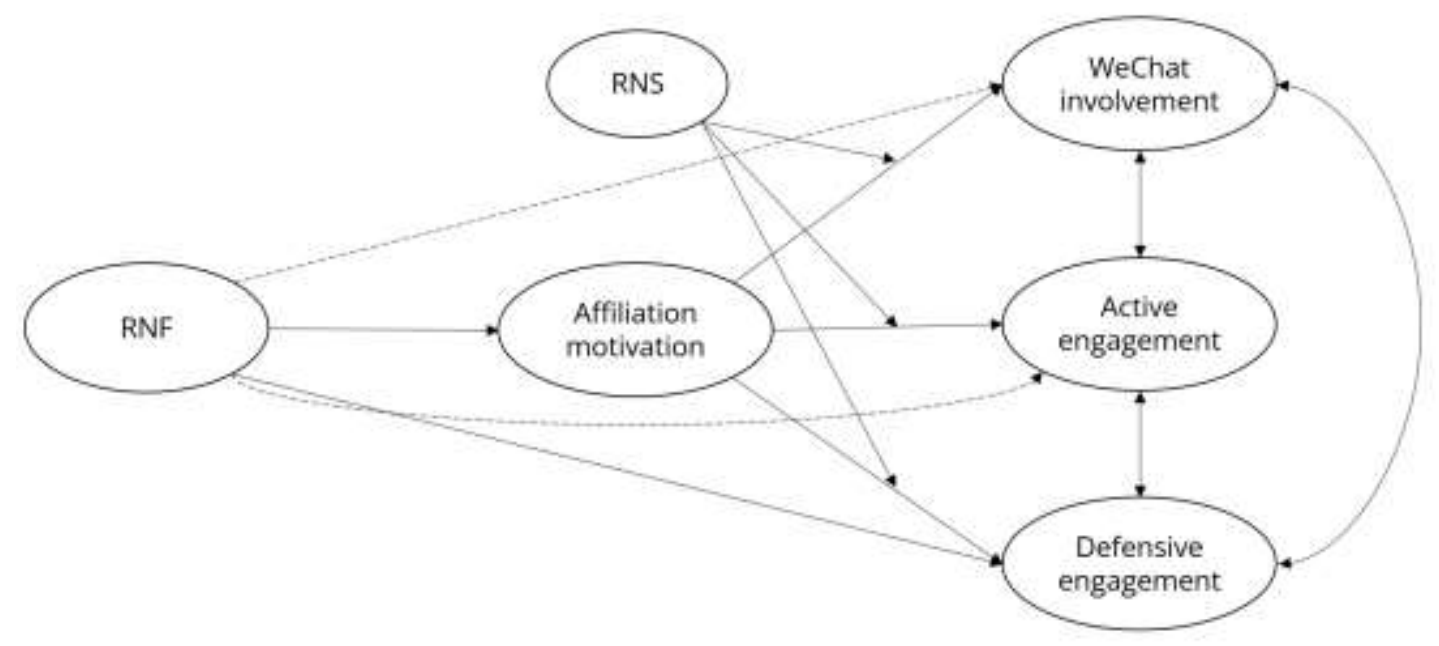

\section{Method}

\section{Participants}

The present study was a cross-sectional study which used online questionnaires. The data were collected in October 2019. Through this convenient sampling method, 530 Chinese students from China Agricultural University were invited to participate in this study. They have different majors (e.g., Agriculture, Applied Chemistry, Biological Engineering, etc.), and there are no students majoring in psychology. All participants were WeChat users; 169 participants used it for more than half a year, 140 for more than one year, and 110 for more than three years.

The valid sample consisted of 494 participants (38.46\% male, $n=190$ ) because 36 students rejected the research invitation. The average age of the participants was $18.81(S D=0.92)$, ranging from 17 to 28 . Students $18(n=176)$ and $19(n=232)$ years of age accounted for the bulk of the research population. The paternal education level of most participants was either high school $(n=257)$ or college level $(n=214)$, and the maternal education levels were similar (high school, $n=312$; college level, $n=164$ ). Most of the parents of the participants are office workers (father, $n=197$; mother, $n=195$ ) and service staff (father, $n=100$; mother, $n=109$ ). Participants were rewarded (2 US dollars) and debriefed after completing the online survey. 


\section{Measures}

\section{Relatedness Frustration and Satisfaction}

The relatedness subscale of the Basic Psychological Need Satisfaction and Frustration Scale was used. The subscale has been validated in China (B. Chen et al., 2015) and includes 8 items. Participants were told to evaluate the degree to which they agree with certain statements. Four items are used to access RNF (e.g., "I feel the relationships I have are superficial", $a=.74, \omega=.81 ; \chi^{2} / d f=4.20, \mathrm{CFI}=.99, \mathrm{TLI}=.96$, RMSEA $=.08, \mathrm{SRMR}=.02$ ), and four items are used to assess RNS (e.g., "I feel close and connected with people who are important to me", $a=.78$, $\left.\omega=.84 ; \chi^{2} / d f=5.06, \mathrm{CFI}=.99, \mathrm{TLI}=.96, \mathrm{RMSEA}=.09, \mathrm{SRMR}=.02\right)$. Participants responded on a 5 -point scale (1 = strongly disagree, 5 = strongly agree), and mean scores were calculated.

\section{Affiliation Motivation}

The Explicit Affiliation Motivation Scale, which was created by McClelland (1991) and validated in China by Xu (2011), was used. Participants were told to assess how important certain statements are to them. The single-dimension scale has 10 items (e.g., "Maintain close, friendly, and cooperative relationships with others", $a=.91, \omega=.92$; $\left.\chi^{2} / d f=4.71, \mathrm{CFI}=.96, \mathrm{TLI}=.94, \mathrm{RMSEA}=.09, \mathrm{SRMR}=.08\right)$. Participants responded on a 7-point scale $(1=$ not important at all, 7 = extremely important), and mean scores were calculated.

\section{WeChat Engagement}

The WeChat Engagement Style Measure, which was developed and validated in China. was used (see all items and scoring details in Appendix A; Y. Chen et al., 2019). Participants were told to review their WeChat engagement and to objectively judge certain questions. The measure has 11 items and three dimensions; 4 items are used to assess involvement (e.g., "Number of chat groups you have joined", $\omega=.77$ ), 4 items are used to assess active engagement (e.g., "Frequency of your posting status updates", $\omega=.88$ ), and 3 items are used to assess defensive engagement (e.g., "Number of people you have blacklisted", $\omega=.89$ ). Participants responded on a 5-point scale $\left(\chi^{2} / d f=4.18\right.$, $\mathrm{CFI}=.94, \mathrm{TLI}=.91, \mathrm{RMSEA}=.08, \mathrm{SRMR}=.06)$. Since the response scores for these 11 items have different meanings (see Appendix A), directly calculating the mean value of a dimension makes this dimension impossible to be interpreted on a uniform scale. Hence, scores of each item were standardized, and an average was calculated (Y. Chen et al., 2019). In the original development of this scale, Chen et al. used model modifications, which violated the independence assumption of calculating Alpha; also, one of the items has the cross loading. This implies that Omega rather than Alpha should be used for this scale's reliability (Geldhof et al., 2014; McNeish, 2018).

\section{Control Variables}

Information on demographics (i.e., gender, age) and socioeconomic status (SES) (i.e., father's and mother's occupation, education level; Bradley \& Corwyn, 2002) was collected. Total duration (years) of WeChat use was also included ( $1=$ within half one year, $n=16 ; 2=$ half to one year, $n=169 ; 3=$ one to two years, $n=140 ; 4=$ two to three years, $n=59 ; 5=$ more than three years, $n=110$ ).

\section{Procedure and Data Analyses}

College students from a psychology class were recruited as participants via research invitation. Specifically, with the teacher's help, the researcher explained to the students the purpose of the research, the approval from the ethics board, and informed consent. If they were willing to participate, they would be given a link that directed them to a webpage hosting the online survey. In the survey, the students provided demographic and socioeconomic information and then answer items in the three scales. If a student was unwilling to participate, he or she did not have to respond to the link. Participants were debriefed and thanked for their participation.

The descriptive analyses were conducted using SPSS 25.0; structural equation modeling (SEM) and the Wald test were conducted by Mplus 7.4. Bias-corrected bootstrap sampling $(k=1000)$ was used to acquire the $95 \%$ confidence interval $(\mathrm{Cl})$. The descriptive analyses included correlational analyses and independent $t$-tests. SEM 
analyses were conducted to test the direct effect model and the indirect mediating model. Latent moderated structural equations were used to explore the moderating role of RNS; the Wald test was used for the simple slope test.

\section{Results}

\section{Descriptive Analyses}

The results of correlational analyses can be seen in Table 1 . Among the control variables, the total duration of WeChat use $(M=3.16, S D=1.21)$ was associated with WeChat involvement $(r=.32, p<.001)$ and active engagement $(r=.15, p<.01)$; gender (coded 1 = male, 2 = female) was associated with RNF $(r=-.20, p<.001)$ and involvement $(r=.10, p<.05)^{1}$.

Table 1. Descriptive and Correlational Results.

\begin{tabular}{|c|c|c|c|c|c|c|}
\hline Research variables & $M(S D)$ & 1 & 2 & 3 & 4 & 5 \\
\hline 1. RNF & $2.47(0.76)$ & - & & & & \\
\hline 2. RNS & $3.82(0.66)$ & $-.40^{* * *}$ & - & & & \\
\hline 3. Affiliation motivation & $5.48(0.86)$ & $-.13^{* *}$ & $.38^{* * \star}$ & - & & \\
\hline 4. Involvement & $0.00(0.71)$ & -.02 & $.13^{* *}$ & $.17^{* * *}$ & - & \\
\hline 5. Active engagement & $0.00(0.81)$ & .03 & $.12^{* \star}$ & $.22^{\star \star *}$ & $.48^{* * *}$ & - \\
\hline 6. Defensive engagement & $0.00(0.87)$ & $.22^{* \star *}$ & -.02 & .00 & $.20^{* * *}$ & $.34^{* * *}$ \\
\hline
\end{tabular}

Note. $N=494 . M$, mean; $S D$, standard deviation. ${ }^{* *} p<.01,{ }^{* * *} p<.001$. The scores of variables 4,5 , and 6 were standardized. The original $M$ and $S D$ information of every item in variable 4, 5, and 6 could be seen in Appendix A.

\section{Mediating Effect of Affiliation Motivation}

Prior to the path analyses, confirmatory factor analysis was conducted. A measurement model with all six scales (relatedness satisfaction, relatedness frustration, affiliation motivation, three WeChat scales) fit adequately $\left(\chi^{2} / d f\right.$ $=2.78, \mathrm{CFI}=.91, \mathrm{TLI}=.90, \mathrm{RMSEA}=.06, \mathrm{SRMR}=.06$ ). All standardized factor loadings of the items ranged from .51 to .85. After control variables were controlled (results of control variables in path analysis were displayed in Appendix B), the direct effect model was created, and it fit well $\left(\chi^{2} / d f=2.61, \mathrm{CFI}=.92, \mathrm{TLI}=.90\right.$, RMSEA $=.06$, SRMR $=.05)$. Path analyses indicated that RNF was significantly related to only defensive engagement $(\beta=.26$, $S E=.07, p<.001,95 \% \mathrm{Cl}=[.12, .40])$ among the three dimensions of WeChat use.

Figure 2. The Mediation Model in the Path Analysis (All Coefficients' 95\% Cls Were Included).

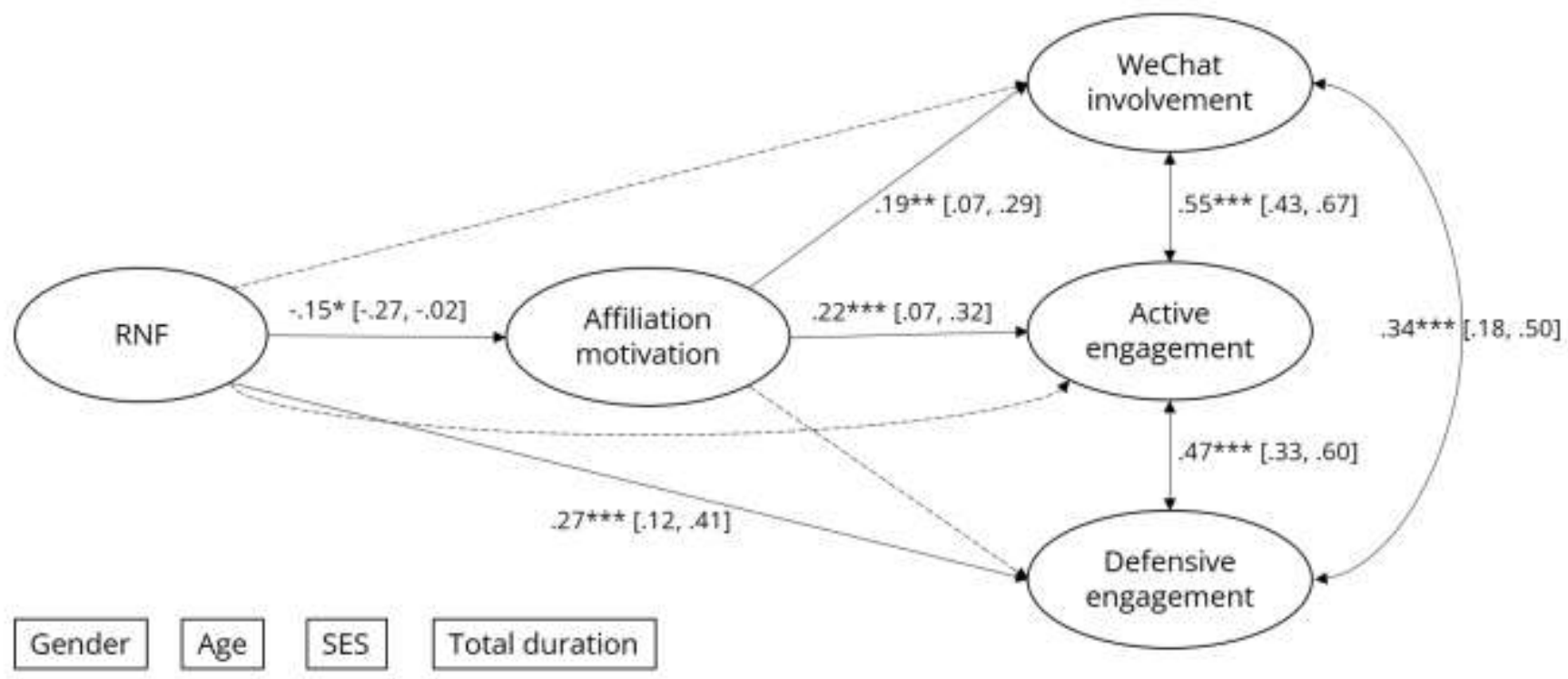


After controlling the same variables and using affiliation motivation as a mediator, the indirect effect model fit well $\left(\chi^{2} / d f=2.54, \mathrm{CFI}=.90, \mathrm{TLI}=.89, \mathrm{RMSEA}=.06, \mathrm{SRMR}=.06\right) . \mathrm{RNF}$ still had a significant relationship with defensive engagement $(\beta=.27, S E=.08, p<.001,95 \% \mathrm{Cl}=[.12, .41])$. Path analyses showed that affiliation motivation mediated the relationship between RNF and WeChat engagement (see Figure 2). Specifically, only the indirect effects from RNF to WeChat involvement and active engagement via affiliation motivation were significant. The former effect was $-0.02(S E=.01, p<.05,95 \% \mathrm{Cl}=[-.06,-.01])$, and the latter was -0.05 (SE $=.02, p<.05,95 \%$ $\mathrm{Cl}=[-.07,-.01])$.

\section{Moderating Effect of RNS}

Based on the method of latent moderated structural equations (Klein \& Moosbrugger, 2000; Muller et al., 2005), the moderating effect of RNS was examined. For the moderation in the path from affiliation motivation to WeChat involvement, there was an acceptable fit in the baseline model $\left(\chi^{2} / d f=2.94, \mathrm{CFI}=.89, \mathrm{TLI}=.87, \mathrm{RMSEA}=.06\right.$, SRMR $=.08$ ). By entering the interaction (affiliation motivation $\times$ RNS) into the baseline model, a new model was produced. The new model fit the data better $\left(D=4.32>\chi^{2}\right.$ critical $\left.=3.84(d f=1)\right)$; the interaction was significantly related to WeChat involvement $(\beta=.11, S E=.05, p<.05)$. The moderating effect of RNS was significant.

Further, to conduct the simple slope test, the Wald test was used, and the results were found to be significant $\left(\chi^{2}=4.23, p<.05\right)$. When participants' RNS was high ( $\left.+1 S D ; M=4.48\right)$, affiliation motivation was positively related to WeChat involvement $(\beta=.21, S E=.10, p<.05)$. When RNS was low $(-1 S D ; M=3.16)$, affiliation motivation was not related to it $(\beta=-.08, S E=.09, p=.39$ ). However, regarding the path from affiliation motivation to active engagement, the interaction was not related to active engagement $(\beta=.08, S E=.05, p=.12)$ in the new model, even though the baseline model had an acceptable fit $\left(\chi^{2} / d f=2.94, \mathrm{CFI}=.89, \mathrm{TLI}=.87, \mathrm{RMSEA}=.06, \mathrm{SRMR}=.08\right)$.

\section{Discussion}

In TPM's framework, this study investigated the motivational and moderation mechanisms in the relationship among relatedness frustration, affiliation motivation, and WeChat engagement. The presented work can be important for understanding motivational aspects of SNSs with regard to the satisfaction and frustration of the basic psychological need for relatedness.

This study found that relatedness frustration was directly related to defensive engagement only, but it was indirectly related to WeChat involvement and active engagement via affiliation motivation. This direct relationship is in line with a previous study of Renren (Zhou, 2014). The feeling of disconnection was found to be related to defensive use, and no relationship was found between disconnection and directed communication (e.g., online messages to friends, reading and commenting on logs). This phenomenon can be explained based on the compensatory patterns of need frustration. Although the social reconnection hypothesis (Maner et al., 2007) suggests that socially rejected people be motivated to contact others, they might show compensatory behaviors such as oppositional defiance (R. M. Ryan et al., 2006). For example, they might break normal social rules in SNSs, be reluctant to participate in online activities, and exhibit negative engagement behaviors. TPM also suggests that people's actual actions could differ from the actions expected during the need-as-motive process when they engage in activities for compensation (Prentice et al., 2014; Sheldon, 2011).

The indirect relationship partially supported the hypotheses; that is, relatedness frustration was not directly related to WeChat involvement and active engagement but rather indirectly related to them through affiliation motivation. The role of affiliation motivation in this indirect relationship is well aligned with TPM's need-as-motive assumption and consistent with the stimulation and social compensation theory (Skues et al., 2012). For relatedness-frustrated individuals, SNSs use was considered compensatory and motivated by the desire to obtain belonging and social closeness (Grieve et al., 2013). These behaviors could help users achieve this goal (Chiou et al., 2014; Lee \& Chiou, 2013). This finding highlights the importance of affiliation motivation, without which subsequent WeChat involvement and active engagement might become ineffective means of coping with relatedness frustration.

Interestingly, the relationship between RNF and affiliation motivation was hypothesized to be positive; however, it turned out to be negative. This finding could be understood and explained from the stress-response adaption 
model and studies in the rejection literature. The adaption model suggests that need frustration has acute and chronic forms (Radel et al., 2011; Selye, 1950). Acute frustration engenders restorative behaviors, but chronic frustration triggers maladjusted motivation and the sense of helplessness. In this study, participants' relatedness frustration might be chronic: they become helpless due to frequent failure to satisfy the relatedness need. In the field of social rejection, it has been well documented that rejection leads to relatedness frustration (Baumeister et al., 2007). Studies have found that social rejection engenders solitude motivation other than affiliation motivation (e.g., Smart Richman \& Leary, 2009; Wesselmann et al., 2014). Socially rejected individuals avoid social interaction to avoid suffering from social pain (Ren et al., 2016). Relatedness frustration could simultaneously trigger the two motivations, and solitude motivation might impact people's evaluation of affiliation motivation, making it possible for relatedness frustration to be negatively related to affiliation motivation.

However, within the indirect relationship between relatedness frustration and defensive engagement, affiliation motivation's mediation was not found, mainly due to the insignificant relationship between affiliation motivation and defensive engagement. In this study, three engagements were found to be positively related to one another: when engaging actively online, users inevitably dislike some people and interact negatively with them (Y. Chen et al., 2019). However, when exploring the link between motivation and engaging style, users are unlikely to engage in active and defensive interactions simultaneously. Compared to defensive engagement, affiliation motivation has a more powerful relationship with involvement and active engagement in SNSs (e.g., building new relationships; H.-T. Chen \& Kim, 2013; Papacharissi \& Mendelsohn, 2011). Therefore, defensive engagement might work as a direct means of coping with relatedness frustration, rather than indirect coping through affiliation motivation.

During mediation, this study identified the moderation effect. The link of affiliation motivation and WeChat involvement exists only in individuals with high relatedness satisfaction. Motivation is related to subsequent behavior, and the result (need satisfaction) of behaviors influences this relationship. In TPM, the moderation of need satisfaction on the need-as-motive process was validated. From the behaviorism perspective, the outcome of certain behaviors determines whether these behaviors reoccur. In SNSs, affiliation motivation stimulates online behaviors, which further satisfy people's relatedness need. Relatedness satisfaction in turn strengthens the relationship between motivation and relatedness-relevant behaviors (Zhou, 2014), such as WeChat involvement. For the relationship between motivation and active engagement, this study did not find significant moderation of relatedness satisfaction. Statistically, it could be seen that the relationship between the interaction (motivation $x$ RNS) and active engagement has a tendency to be marginally significant $(p=.12)$. Compared to active engagement, the relationship between motivation and involvement might be more sensitive to relatedness satisfaction. Driven by affiliation motivation, people with different levels of relatedness satisfaction to show different levels of involvement in WeChat.

\section{Limitations and Practical Implications}

The present study explored the relationships among relatedness frustration, affiliation motivation, and WeChat engagement; moderation mechanism was also examined. Using social media platforms such as WeChat seems to be a strategy for coping with relatedness frustration. People might cope with it directly through defensive WeChat use or indirectly through involvement and active use by activating affiliation motivation. Within this motivational mechanism, relatedness satisfaction impacts this coping process after relatedness frustration, especially in the link between affiliation motivation and involvement.

Next, the limitations and practical implications of this study will be discussed. First, this study is a cross-sectional study and thus the results cannot explain the causal relationships among key variables. This interfered with fully validating TPM's interaction assumption that prior RNS experience interacts with subsequent motivation to relate to WeChat engagement. Future studies might consider validating the moderated mediation model via experimental and longitudinal approaches (Sheldon \& Schüler, 2011). For example, relatedness frustration can be manipulated in the lab (Knowles et al., 2015; Lee \& Chiou, 2013). Furthermore, this study uses a convenient sampling method, and all participants are Chinese college students and WeChat users. Restricting the sample to one country and one specific group of users limits the generalizability of findings. In the future, cross-cultural studies can be conducted using wider groups of SNSs users. In addition, the key variables were all self-reported, 
and measurement validity could be impacted by the social-desirability bias (Fisher \& Katz, 2000). Future research might use the implicit association test (IAT) to assess affiliation motivation.

Second, this study explores only one motivation component (affiliation motivation) of SNSs engagement. In future studies, other motivations, such as the power motivation, can be considered (Heser et al., 2015). In SNSs, people with high power motivation would take initiative, put themselves in a favorable position, and control the online interaction process with others. Additionally, autonomous motivation and controlled motivation of the selfdetermination theory (Trépanier et al., 2015; Tsoi et al., 2018) should be considered in future research. Autonomous motivation is the behavioral motivation driven by a high level of self-determination, and relatedness satisfaction fosters it, while controlled motivation is driven by a low level of self-determination, and relatedness frustration leads to it. Several studies (Fernet et al., 2013; Mouratidis et al., 2011) have explored the relationships among need satisfaction/frustration, autonomous/controlled motivation, and the outcomes of individual's personal wellness in various contexts (e.g., work, school). Additionally, this study focused on the association of relatedness frustration and affiliation motivation with SNSs behaviors, but the way in which these behaviors satisfy users was not considered. Some studies found that using SNSs improved well-being and flow (F. Jiang \& J. Z. Jiang, 2015; Wen et al., 2016). Importantly, SNSs engagement is not always beneficial: excessive use might lead to addiction (Hou et al., 2017; Hou et al., 2018).

Furthermore, of the three basic psychological needs (i.e., autonomy, competence, and relatedness; Deci \& R. M. Ryan, 2008), this study examines only the role of relatedness, as the frustration of this need is related to motivation and WeChat use, and its satisfaction moderates the link between motivation and WeChat involvement. However, the three basic needs are working jointly rather than separately. Zhou (2014) has found that relatedness frustration is related to competence frustration and in turn related to passive Renren engagement. Users experience a low level of self-efficacy due to frustrated relatedness need. As a result, they lack the confidence to actively engage in Renren activities. Future research might consider the moderation role of competence need based on the conceptual model of this study. Also, another use style, passive engagement, has attracted a great deal of attention in the field of SNSs (e.g., Trifiro \& Gerson, 2019; Wang et al., 2018; Yu, 2016). It was defined as a lack of SNSs behavioral engagement such as browsing and consuming content without interacting with others (Kaye, 2021; T. Ryan et al., 2017). However, in Chinese culture, defensive engaging behaviors are considered as self-protective. Individuals behave like this aiming to keep their status updates from being seen by those who are perceived as threatening, or as a defensive response to not seeing content that is not of interest. Through these behaviors, people protect their sense of SNSs security. Future studies might examine and compare the four SNSs engagement styles (i.e., involvement, active use, passive use, and defensive use).

Finally, TPM suggests the other interaction in the need-as-requirement process. That is, the link between need satisfaction and context-specific wellness could be moderated by a person's motivation. For example, Schüler et al. (2013) found moderating effect in achievement motivation in the relationship between competence satisfaction and flow. Individuals with high achievement motivation could more easily achieve flow from competence satisfaction. Future research concerning this issue could be carried out. Given that this study was conducted in Chinese university students, it should be careful when generalizing the findings to other groups. Also, doing a study in one country has its own limitations, since there are major cultural differences in psychological functioning among people from different cultures. This study aims to verify the theoretical hypothesis of TPM in Chinese culture (WeChat), which has been verified in Western culture (Facebook). At the behavioral level, individuals in both cultures show consistency, that is, they all use SNSs to cope with RNF. However, at the motivational level, there was a negative association between RNF and affiliation motivation in Chinese culture, while it was positive in Western culture (Sheldon et al., 2011). For Chinese participants, they lack the motivation of belonging caused by RNF, but they seem to behave similarly to Western culture. This is an interesting and valuable topic for future research.

\section{Footnotes}

1. With independent $t$-tests, it was further found that males reported higher RNF $(M=2.67, S D=0.75 ; t=4.76$, $p<.001$, Cohen's $d=0.44)$ and lower involvement $(M=-0.09, S D=0.72 ; t=-2.37, p<.05$, Cohen's $d=-0.21)$ than females $(M=2.34, S D=0.74 ; M=0.06, S D=0.71)$. 


\section{Disclosure Statement}

The authors report no potential conflicts of interest.

\section{Data Availability Statement}

The data that support the findings of this study are available from the corresponding author upon reasonable request.

\section{References}

Baumeister, R. F., Brewer, L. E., Tice, D. M., \& Twenge, J. M. (2007). Thwarting the need to belong: Understanding the interpersonal and inner effects of social exclusion. Social and Personality Psychology Compass, 1(1), 506-520. https://doi.org/10.1111/j.1751-9004.2007.00020.x

Baumeister, R. F., \& Leary, M. R. (1995). The need to belong: Desire for interpersonal attachments as a fundamental human motivation. Psychological Bulletin, 117(3), 497-529. https://doi.org/10.1037/00332909.117.3.497

Bradley, R. H., \& Corwyn, R. F. (2002). Socioeconomic status and child development. Annual Review of Psychology, 53, 371-399. https://doi.org/10.1146/annurev.psych.53.100901.135233

Chen, B., Vansteenkiste, M., Beyers, W., Boone, L., Deci, E. L., \& Van der Kaap-Deeder, J., Duriez, B., Lens, W., Matos, L., Mouratidis, A., Ryan, R. M., Sheldon, K. M., Soenens, B., Van Petegem, S., \& Verstuyf, J. (2015). Basic psychological need satisfaction, need frustration, and need strength across four cultures. Motivation and Emotion, 39(2), 216-236. https://doi.org/10.1007/s11031-014-9450-1

Chen, H.-T., \& Kim, Y. (2013). Problematic use of social network Sites: The interactive relationship between gratifications sought and privacy concerns. Cyberpsychology, Behavior, and Social Networking, 16(11), 806-812. https://doi.org/10.1089/cyber.2011.0608

Chen, Y., Li, R., Zhang, P., \& Liu, X. (2019). WeChat engagement styles: Measuring the two processes of relatedness need, moderated by personality differences. Current Psychology. Advance online publication. https://doi.org/10.1007/s12144-019-00513-5

Chester, D. S., DeWall, C. N., \& Pond, R. S., Jr. (2016). The push of social pain: Does rejection's sting motivate subsequent social reconnection? Cognitive, Affective, \& Behavioral Neuroscience, 16(3), 541-550.

https://doi.org/10.3758/s13415-016-0412-9

Chiou, W.-B., Chen, S.-W., \& Liao, D.-C. (2014). Does Facebook promote self-interest? Enactment of indiscriminate one-to-many communication on online social networking sites decreases prosocial behavior. Cyberpsychology, Behavior, and Social Networking, 17(2), 68-73. https://doi.org/10.1089/cyber.2013.0035

Chiou, W.-B., Lee, C.-C., \& Liao, D.-C. (2015). Facebook effects on social distress: Priming with online social networking thoughts can alter the perceived distress due to social exclusion. Computers in Human Behavior, 49, 230-236. https://doi.org/10.1016/j.chb.2015.02.064

Cordeiro, P., Paixão, P., Lens, W., Lacante, M., \& Sheldon, K. M. (2016). Factor structure and dimensionality of the balanced measure of basic psychological needs among Portuguese high school students. Relations to well-being and ill-being. Learning and Individual Differences, 47, 51-60. https://doi.org/10.1016/j.lindif.2015.12.010

Deci, E. L., \& Ryan, R. M. (2008). Facilitating optimal motivation and psychological well-being across life's domains. Canadian Psychology, 49(1), 14-23. https://doi.org/10.1037/0708-5591.49.1.14 
Fang, H., He, B., Fu, H., Zhang, H., Mo, Z., \& Meng, L. (2018). A surprising source of self-motivation: Prior competence frustration strengthens one's motivation to win in another competence-supportive activity. Frontiers in Human Neuroscience, 12, Article 314. https://doi.org/10.3389/fnhum.2018.00314

Fernet, C., Austin, S., Trépanier, S.-G., \& Dussault, M. (2013). How do job characteristics contribute to burnout? Exploring the distinct mediating roles of perceived autonomy, competence, and relatedness. European Journal of Work \& Organizational Psychology, 22(2), 123-137. https://doi.org/10.1080/1359432X.2011.632161

Fisher, R. J., \& Katz, J. E. (2000). Social-desirability bias and the validity of self-reported values. Psychology \& marketing, 17(2), 105-120. https://doi.org/10.1002/(SICI)1520-6793(200002)17:2<105::AID-MAR3>3.0.CO;2-9

Geldhof, G. J., Preacher, K. J., \& Zyphur, M. J. (2014). Reliability estimation in a multilevel confirmatory factor analysis framework. Psychological Methods, 19(1), 72-91. https://doi.org/10.1037/a0032138

Gerber, J., \& Wheeler, L. (2009). On being rejected: A meta-analysis of experimental research on rejection. Perspectives on Psychological Science, 4(5), 468-488. https://doi.org/10.1111/j.1745-6924.2009.01158.x

Gerson, J., Plagnol, A. C., \& Corr, P. J. (2017). Passive and Active Facebook Use Measure (PAUM): Validation and relationship to the reinforcement sensitivity theory. Personality and Individual Differences, 117, 81-90.

https://doi.org/10.1016/j.paid.2017.05.034

Grieve, R., Indian, M., Witteveen, K., Tolan, G. A., \& Marrington, J. (2013). Face-to-face or Facebook: Can social connectedness be derived online? Computers in Human Behavior, 29(3), 604-609.

https://doi.org/10.1016/j.chb.2012.11.017

He, J. B., Zhu, P. P, Nie, Y. F., \& Ying, S. Y. (2017). The influence of personality on internet addiction and its psychological mechanisms: A review. Chinese Journal of Clinical Psychology, 25, 221-224.

Heser, K., Banse, R., \& Imhoff, R. (2015). Affiliation or power: What motivates behavior on social networking sites? Swiss Journal of Psychology, 74(1), 37-47. https://doi.org/10.1024/1421-0185/a000144

Hou, J., Ndasauka, Y., Jiang, Y., Ye, Z., Wang, Y., \& Yang, Li, X., Zhang, Y., Pang, L., Kong, Y., Xu, F., \& Zhang, X. (2017). Excessive use of WeChat, social interaction and locus of control among college students in China. Plos One, 12(8), Article e0183633. https://doi.org/10.1371/journal.pone.0183633

Hou, J., Ndasauka, Y., Pan, X., Chen, S., Xu, F., \& Zhang, X. (2018). Weibo or WeChat? Assessing preference for social networking sites and role of personality traits and psychological factors. Frontiers in Psychology, 9, Article 545. https://doi.org/10.3389/fpsyg.2018.00545

Hughes, D. J., Rowe, M., Batey, M., \& Lee, A. (2012). A tale of two sites: Twitter vs. Facebook and the personality predictors of social media usage. Computers in Human Behavior, 28(2), 561-569.

https://doi.org/10.1016/j.chb.2011.11.001

Jiang, F., Jiang, J. Z. (2015). Moderating effect of social networking site users' implicit affiliation motivation on the relationship between social interaction ties expectation confirmation and flow experience. Journal of Shanghai Jiaotong University, 23, 104-112.

Jiang, Y. Z., Bai, X. L., Liu, Y., \& Chen, Z. Y. (2017). Effect of social adaptability on the use of mobile social networks in adolescents: Chain mediating effect of self identity and mental harmony. Chinese Journal of Clinical Psychology, $25,550-553$.

Kaye, L. K. (2021). Exploring the "socialness" of social media. Computers in Human Behavior Reports, 3, Article 100083. https://doi.org/10.1016/j.chbr.2021.100083 
Klein, A., \& Moosbrugger, H. (2000). Maximum likelihood estimation of latent interaction effects with the LMS method. Psychometrika, 65(4), 457-474. https://doi.org/10.1007/BF02296338

Knowles, M. L., Haycock, N., \& Shaikh, I. (2015). Does Facebook magnify or mitigate threats to belonging? Social Psychology, 46(6), 313-324. https://doi.org/10.1027/1864-9335/a000246

Langan-Fox, J., \& Grant, S. (2006). The Thematic Apperception Test: Toward a standard measure of the big three motives. Journal of Personality Assessment, 87(3), 277-291. https://doi.org/10.1207/s15327752jpa8703_09

Lee, C.-C., \& Chiou, W.-B. (2013). Keep logging in! Experimental evidence showing the relation of affiliation needs to the idea of online social networking. Cyberpsychology, Behavior, and Social Networking, 16(6), 419-422.

https://doi.org/10.1089/cyber.2012.0544

Maner, J. K., DeWall, C. N., Baumeister, R. F., \& Schaller, M. (2007). Does social exclusion motivate interpersonal reconnection? Resolving the "porcupine problem." Journal of Personality and Social Psychology, 92(1), 42-55. https://doi.org/10.1037/0022-3514.92.1.42

McClelland, D. C. (1991). The personal value questionnaire. McBer \& Company.

McNeish, D. (2018). Thanks coefficient alpha, we'll take it from here. Psychological Methods, 23(3), 412-433. https://doi.org/10.1037/met0000144

Moller, A. C., Deci, E. L., \& Elliot, A. J. (2010). Person-level relatedness and the incremental value of relating. Personality and Social Psychology Bulletin, 36(6), 754-767. https://doi.org/10.1177/0146167210371622

Mouratidis, A. A., Vansteenkiste, M., Sideridis, G., \& Lens, W. (2011). Vitality and interest-enjoyment as a function of class-to-class variation in need-supportive teaching and pupils' autonomous motivation. Journal of Educational Psychology, 103(2), 353-366. https://doi.org/10.1037/a0022773

Muller, D., Judd, C. M., \& Yzerbyt, V. Y. (2005). When moderation is mediated and mediation is moderated. Journal of Personality and Social Psychology, 89(6), 852-863. https://doi.org/10.1037/0022-3514.89.6.852

Neubauer, A. B., Voss, A., \& Ditzen, B. (2018). Exploring need dynamics within and across days in everyday life: A three-level analysis. Journal of Research in Personality, 77, 101-112. https://doi.org/10.1016/j.jrp.2018.10.001

Papacharissi, Z., \& Mendelsohn, A. (2011). Toward a new(er) sociability: Uses, gratifications and social capital on Facebook. In S. Papathanassopoulos (Ed.), Communication and society: Media perspectives for the 21st century: Concepts, topics and issues (pp. 212-230). Routledge.

Park, N., Jin, B., \& Jin, S.-A. A. (2011). Effects of self-disclosure on relational intimacy in Facebook. Computers in Human Behavior, 27(5), 1974-1983. https://doi.org/10.1016/j.chb.2011.05.004

Prentice, M., Halusic, M., \& Sheldon, K. M. (2014). Integrating theories of psychological needs-as-requirements and psychological needs-as-motives: A two process model. Social and Personality Psychology Compass, 8(2), 73-85. https://doi.org/10.1111/spc3.12088

Qiu, L., Lin, H., \& Leung, A. K.-Y. (2013). Cultural differences and switching of in-group sharing behavior between an American (Facebook) and a Chinese (Renren) social networking site. Journal of Cross-Cultural Psychology, 44(1), 106-121. https://doi.org/10.1177/0022022111434597

Radel, R., Pelletier, L. G., Sarrazin, P., \& Milyavskaya, M. (2011). Restoration process of the need for autonomy: The early alarm stage. Journal of Personality and Social Psychology, 101(5), 919-934.

https://doi.org/10.1037/a0025196 
Ren, D., Wesselmann, E., \& Williams, K. D. (2016). Evidence for another response to ostracism: Solitude seeking. Social Psychological and Personality Science, 7(3), 204-212. https://doi.org/10.1177/1948550615616169

Ryan, R. M., Deci, E. L., Grolnick, W. S., \& La Guardia, J. G. (2006). The significance of autonomy and autonomy support in psychological development and psychopathology. In D. Cicchetti \& D. J. Cohen (Eds.), Developmental psychopathology: Theory and methods (Vol. 1, 2nd ed., pp. 795-849). John Wiley \& Sons, Inc.

Ryan, T., Allen, K. A., Gray, D. L., \& McInerney, D. M. (2017). How social are social media? A review of online social behaviour and connectedness. Journal of Relationships Research, 8, Article e8. https://doi.org/10.1017/jrr.2017.13

Schüler, J., Brandstätter, V., \& Sheldon, K. M. (2013). Do implicit motives and basic psychological needs interact to predict well-being and flow? Testing a universal hypothesis and a matching hypothesis. Motivation and Emotion, 37(3), 480-495. https://doi.org/10.1007/s11031-012-9317-2

Schüler, J., Sheldon, K. M., \& Fröhlich, S. M. (2010). Implicit need for achievement moderates the relationship between competence need satisfaction and subsequent motivation. Journal of Research in Personality, 44(1), 1-12. https://doi.org/10.1016/j.jrp.2009.09.002

Selye, H. (1950). Stress and the general adaptation syndrome. British Medical Journal, 1, 1383-1392. https://doi.org/10.1136/bmj.1.4667.1383

Sheldon, K. M. (2011). Integrating behavioral-motive and experiential-requirement perspectives on psychological needs: A two process model. Psychological Review, 118(4), 552-569. https://doi.org/10.1037/a0024758

Sheldon, K. M., Abad, N., \& Hinsch, C. (2011). A two-process view of Facebook use and relatedness needsatisfaction: Disconnection drives use, and connection rewards it. Journal of Personality and Social Psychology, 100(4), 766-775. https://doi.org/10.1037/a0022407

Sheldon, K. M., \& Schüler, J. (2011). Wanting, having, and needing: Integrating motive disposition theory and selfdetermination theory. Journal of Personality and Social Psychology, 101(5), 1106-1123.

https://dx.doi.org/10.1037/a0024952

Skues, J. L., Williams, B., \& Wise, L. (2012). The effects of personality traits, self-esteem, loneliness, and narcissism on Facebook use among university students. Computers in Human Behavior, 28(6), 2414-2419.

https://doi.org/10.1016/j.chb.2012.07.012

Smart Richman, L., \& Leary, M. R. (2009). Reactions to discrimination, stigmatization, ostracism, and other forms of interpersonal rejection: A multimotive model. Psychological Review, 116(2), 365-383.

https://doi.org/10.1037/a0015250

Smith, A. G. (2008). The implicit motives of terrorist groups: How the needs for affiliation and power translate into death and destruction. Political Psychology, 29(1), 55-75. https://doi.org/10.1111/j.1467-9221.2007.00612.x

Sultan, A. J. (2014). Addiction to mobile text messaging applications is nothing to "Iol" about. Social Science Journal, 51(1), 57-69. https://doi.org/10.1016/j.soscij.2013.09.003

Trépanier, S.-G., Forest, J., Fernet, C., \& Austin, S. (2015). On the psychological and motivational processes linking job characteristics to employee functioning: Insights from self-determination theory. Work \& Stress, 29(3), 286305. https://doi.org/10.1080/02678373.2015.1074957

Trifiro, B. M., \& Gerson, J. (2019). Social media usage patterns: Research note regarding the lack of universal validated measures for active and passive use. Social Media + Society, 5(2).

https://doi.org/10.1177/2056305119848743 
Tsoi, S. L. T. A., de Boer, A., Croiset, G., Koster, A. S., van der Burgt, S., \& Kusurkar, R. A. (2018). How basic psychological needs and motivation affect vitality and lifelong learning adaptability of pharmacists: A structural equation model. Advances in Health Sciences Education, 23(3), 549-566. https://doi.org/10.1007/s10459-018-98127

Van Petegem, S., Vansteenkiste, M., \& Beyers, W. (2013). The Jingle-Jangle fallacy in adolescent autonomy in the family: In search of an underlying structure. Journal of Youth and Adolescence, 42(7), 994-1014.

https://doi.org/10.1007/s10964-012-9847-7

Vansteenkiste, M., \& Ryan, R. M. (2013). On psychological growth and vulnerability: Basic psychological need satisfaction and need frustration as a unifying principle. Journal of Psychotherapy Integration, 23(3), 263-280. https://doi.org/10.1037/a0032359

Wang, J.-L., Gaskin, J., Rost, D. H., \& Gentile, D. A. (2018). The reciprocal relationship between passive social networking site (SNS) usage and users' subjective well-being. Social Science Computer Review, 36(5), 511-522. https://doi.org/10.1177/0894439317721981

Wen, Z., Geng, X., \& Ye, Y. (2016). Does the use of WeChat lead to subjective well-being: The effect of use intensity and motivations. Cyberpsychology, Behavior, and Social Networking, 19(10), 587-592.

https://doi.org/10.1089/cyber.2016.0154

Wesselmann, E. D., Williams, K. D., Ren, D., \& Hales, A. H. (2014). Ostracism and solitude. In R. J. Coplan \& J. Bowker (Eds.), A handbook of solitude: Psychological perspectives on social isolation, social withdrawal, and being alone (pp. 224-241). Wiley-Blackwell.

Williams, K. D. (2009). Ostracism: A temporal need-threat model. Advances in Experimental Social Psychology, 41, 275-314. https://doi.org/10.1016/S0065-2601(08)00406-1

$\mathrm{Xu}, \mathrm{H}$. (2011). A research on the relationships between college students' implicit/explicit affiliation motivation and emotional well-being (Unpublished doctoral dissertation). Southwest University.

Yu, R. P. (2016). The relationship between passive and active non-political social media use and political expression on Facebook and Twitter. Computers in Human Behavior, 58, 413-420.

https://doi.org/10.1016/j.chb.2016.01.019

Zhou, J. (2014). Modern psychology research on human basic psychological needs (Unpublished doctoral dissertation). Wuhan University. 


\section{Appendix A}

Table 2. Items and Descriptive Information of WeChat Engagement Style Measure (Chen et al., 2019).

\begin{tabular}{|c|c|c|c|c|c|c|}
\hline Items & $M(S D)$ & 1 & 2 & 3 & 4 & 5 \\
\hline 1. Number of friends you have & $\begin{array}{l}1.47 \\
(.59)\end{array}$ & 100 or less & $101-300$ & $301-500$ & $501-800$ & More than 800 \\
\hline $\begin{array}{l}\text { 2. Number of chat groups you have } \\
\text { joined }\end{array}$ & $\begin{array}{c}1.91 \\
(1.00)\end{array}$ & 10 or less & $11-20$ & $21-30$ & $31-50$ & More than 50 \\
\hline 3. Your frequency of chatting & $\begin{array}{c}2.79 \\
(1.22)\end{array}$ & Once a week & $\begin{array}{l}\text { Several } \\
\text { times a } \\
\text { week }\end{array}$ & $\begin{array}{l}\text { Once a } \\
\text { day }\end{array}$ & $\begin{array}{l}\text { Many } \\
\text { times a } \\
\text { day }\end{array}$ & $\begin{array}{l}\text { Dozens of } \\
\text { times a day }\end{array}$ \\
\hline 4. Your daily average use time (hours) & $\begin{array}{c}2.01 \\
(1.12)\end{array}$ & Less than 1 & $1-2$ & $2-3$ & $3-5$ & More than 5 \\
\hline $\begin{array}{l}\text { 5. Your frequency of commenting on } \\
\text { others' status updates }\end{array}$ & $\begin{array}{c}2.61 \\
(1.44)\end{array}$ & $\begin{array}{l}\text { Once a } \\
\text { month or } \\
\text { less }\end{array}$ & Once a week & $\begin{array}{l}\text { 3-4 times } \\
\text { a week }\end{array}$ & $\begin{array}{l}\text { Once a } \\
\text { day }\end{array}$ & $\begin{array}{l}\text { Many times a } \\
\text { day or more }\end{array}$ \\
\hline $\begin{array}{l}\text { 6. Your frequency of posting status } \\
\text { updates }\end{array}$ & $\begin{array}{c}1.92 \\
(1.17)\end{array}$ & $\begin{array}{l}\text { Once a } \\
\text { month or } \\
\text { less }\end{array}$ & Once a week & $\begin{array}{l}\text { 3-4 times } \\
\text { a week }\end{array}$ & $\begin{array}{l}\text { Once a } \\
\text { day }\end{array}$ & $\begin{array}{l}\text { Many times a } \\
\text { day or more }\end{array}$ \\
\hline $\begin{array}{l}\text { 7. Your frequency of "liking" others' } \\
\text { status updates }\end{array}$ & $\begin{array}{c}3.11 \\
(1.50)\end{array}$ & $\begin{array}{l}\text { Once a } \\
\text { month or } \\
\text { less }\end{array}$ & Once a week & $\begin{array}{l}\text { 3-4 times } \\
\text { a week }\end{array}$ & $\begin{array}{l}\text { Once a } \\
\text { day }\end{array}$ & $\begin{array}{l}\text { Many times a } \\
\text { day or more }\end{array}$ \\
\hline $\begin{array}{l}\text { 8. Your frequency of sharing content } \\
\text { on "Moments" }\end{array}$ & $\begin{array}{c}1.70 \\
(1.10)\end{array}$ & $\begin{array}{l}\text { Once a } \\
\text { month or } \\
\text { less }\end{array}$ & Once a week & $\begin{array}{l}\text { 3-4 times } \\
\text { a week }\end{array}$ & $\begin{array}{l}\text { Once a } \\
\text { day }\end{array}$ & $\begin{array}{l}\text { Many times a } \\
\text { day or more }\end{array}$ \\
\hline $\begin{array}{l}\text { 9. Number of people whose status } \\
\text { updates you have hidden }\end{array}$ & $\begin{array}{l}1.32 \\
(.78)\end{array}$ & $0-5$ & $6-15$ & $16-30$ & $31-50$ & More than 50 \\
\hline $\begin{array}{l}\text { 10. Number of people you have } \\
\text { blocked from seeing your status } \\
\text { updates }\end{array}$ & $\begin{array}{l}1.40 \\
(.88)\end{array}$ & $0-5$ & $6-15$ & $16-30$ & $31-50$ & More than 50 \\
\hline $\begin{array}{l}\text { 11. Number of people you have } \\
\text { blocked }\end{array}$ & $\begin{array}{l}1.15 \\
(.56)\end{array}$ & $0-5$ & $6-15$ & $16-30$ & $31-50$ & More than 50 \\
\hline
\end{tabular}

Note. Items 1-4 are used to assess WeChat involvement, items 5-8 for active engagement, and items 9-11 for defensive engagement.

\section{Appendix B}

Table 3. Results of Control Variables in Path Analysis.

\begin{tabular}{|c|c|c|c|c|c|c|c|}
\hline \multirow{2}{*}{ Dependent variables } & \multirow{2}{*}{ Control variables } & \multicolumn{3}{|c|}{ Direct effect model } & \multicolumn{3}{|c|}{ Indirect effect model } \\
\hline & & $\beta$ & $S E$ & $p$ & $\beta$ & $S E$ & $p$ \\
\hline \multirow[t]{4}{*}{ Involvement } & Gender & .12 & .05 & .031 & .12 & .05 & .031 \\
\hline & Age & .07 & .04 & .073 & .06 & .04 & .121 \\
\hline & SES & .02 & .05 & .730 & .02 & .05 & .700 \\
\hline & Total duration & .39 & .05 & .000 & .39 & .05 & .000 \\
\hline \multirow[t]{4}{*}{ Active engagement } & Gender & -.01 & .05 & .874 & -.01 & .05 & .838 \\
\hline & Age & .04 & .05 & .404 & .03 & .05 & .576 \\
\hline & SES & -.02 & .05 & .690 & -.02 & .05 & .732 \\
\hline & Total duration & .13 & .05 & .011 & .13 & .05 & .011 \\
\hline \multirow[t]{4}{*}{ Defensive engagement } & Gender & .02 & .05 & .700 & .02 & .05 & .699 \\
\hline & Age & .01 & .07 & .844 & .01 & .07 & .865 \\
\hline & SES & .03 & .05 & .605 & .03 & .05 & .602 \\
\hline & Total duration & -.02 & .06 & .770 & -.02 & .06 & .766 \\
\hline
\end{tabular}




\section{Correspondence to:}

Xiangping Liu

Faculty of Psychology, Beijing Normal University

No.19 Xinjiekouwai Street

Beijing, 100875

PR China

Email: xpliu599(at)163.com

Editorial record: First submission received on December 14, 2020. Revision received on July 18, 2021. Accepted for publication on October 4, 2021.

Editor in charge: David Smahel

\section{About Authors}

Yunxiang Chen is a Ph.D. student at the University of Rochester and is interested in benevolence, happiness, selfdetermination theory, and positive psychology.

Ruoxuan Li is a Ph.D. student at the University of Notre Dame and is interested in student learning motivation, teacher mental health, and well-being.

Xiangping Liu is a professor at Beijing Normal University. His research interests include social anxiety, reading disorder, attachment theory, and positive psychology.

(C) Author(s). The articles in Cyberpsychology: Journal of Psychosocial Research on Cyberspace are open access articles licensed under the terms of the Creative Commons BY-NC-ND 4.0 International License which permits unrestricted, non-commercial use, distribution and reproduction in any medium, provided the work is properly cited. 